\title{
Design, development and evaluation of novel nanoemulsion formulations for transdermal potential of celecoxib
}

\author{
SANJULA BABOOTA \\ FAIYAZ SHAKEEL* \\ ALKA AHUJA \\ JAVED ALI \\ SHEIKH SHAFIQ \\ Department of Pharmaceutics
Faculty of Pharmacy
Jamia Hamdard (Hamdard University)
New Delhi-110062, India
}

Accepted April 12, 2007

\begin{abstract}
The aim of the present study was to investigate the potential of nanoemulsion formulations for transdermal delivery of celecoxib (CXB). The in vitro skin permeation profile of optimized formulations was compared with CXB gel and nanoemulsion gel. Significant increase in the steady state flux $\left(J_{\mathrm{ss}}\right)$, permeability coefficient $\left(K_{\mathrm{p}}\right)$ and enhancement ratio $\left(E_{\mathrm{r}}\right)$ was observed in nanoemulsion formulations T1 and T2 $(p<0.05)$. The highest value of these permeability parameters was obtained in formulation T2, which consisted of $2 \%(\mathrm{~m} / \mathrm{m})$ of CXB, $10 \%(\mathrm{~m} / \mathrm{m})$ of oil phase (Sefsol 218 and Triacetin), 50\% $(\mathrm{m} / \mathrm{m})$ of surfactant mixture (Tween-80 and Transcutol-P) and $40 \%$ $(\mathrm{m} / \mathrm{m})$ water. The anti-inflammatory effects of formulation T2 showed a significant increase $(p<0.05)$ in inhibition after $24 \mathrm{~h}$ compared to CXB gel and nanoemulsion gel on carrageenan-induced paw edema in rats. These results suggested that nanoemulsions are potential vehicles for improved transdermal delivery of CXB.
\end{abstract}

Keywords: celecoxib, nanoemulsions, microemulsions, nanoemulsion gels, transdermal delivery, anti-inflammatory effect

Nonsteroidal anti-inflammatory drugs (NSAIDs) are the most commonly used drugs to reduce pain and inflammation (1). Celecoxib (CXB), a selective cyclo-oxygenase-2 (COX-2) inhibitor, has been recommended orally for the treatment of arthritis and osteoarthritis (2). Long-term oral administration of CXB causes serious gastrointestinal side effects (2). Furthermore, poor aqueous solubility of $\mathrm{CXB}$ limits its formulation as topical dosage forms. Therefore, an improved CXB formulation with a high degree of permeation could be useful in the treatment of locally inflamed skin and inflammatory and painful states of the body, like bones, ligaments, etc. Topical vehicle systems can modify drug permeation through the skin but many dermal vehicles contain chemical enhancers and solvents to achieve these goals (3). The use of these chemical enhancers may be harmful especially in chronic applications, since many of them are usually irritants. It is therefore desirable to develop a topical vehicle system, that does not necessitate the

\footnotetext{
* Correspondence, e-mail: faiyazs@fastmail.fm
} 
use of chemical enhancers to facilitate drug permeation through the skin. One of the most promising techniques for enhancement of transdermal permeation of drugs is the microemulsion or nanoemulsion technique $(4,5)$. Nanoemulsions are thermodynamically stable transparent (translucent) dispersions of oil and water stabilized by an interfacial film of surfactant and cosurfactant molecules having the droplet size less than $100 \mathrm{~nm}(6,7)$. Studies have shown that nanoemulsion formulations possess improved transdermal and dermal delivery properties in vitro $(8-10)$ and in vivo $(11,12)$ over emulsions $(12)$ and gels $(13,14)$. This paper describes the potential of the nanoemulsion system in transdermal delivery of $\mathrm{CXB}$ using nonirritant, pharmaceutically acceptable ingredients without additional permeation enhancers because components of nanoemulsions themselves act as permeation enhancers.

\section{EXPERIMENTAL}

\section{Materials}

Celecoxib (CXB) was a kind gift from Ranbaxy Research Labs (India). Caprylic/capric triglyceride polyethylene glycol-4 complex (Labrafac), caprylo caproyl macrogol-8-glyceride (Labrasol), polyglyceryl-6-dioleate (Plurol oleique), jojoba oil and oleoyl macroglycerides EP (Labrafil) were kind gift samples from Gattefossé (France), propylene glycol mono caprylic ester (Sefsol 218) was kind gift sample from Nikko Chemicals (Japan). Isopropyl myristate (IPM), glycerol triacetate (Triacetin), olive oil, diethylene glycol monoethyl ether (Transcutol-P) and methanol (HPLC grade) were purchased from Merck (India). Tween-80 was purchased from Sigma Aldrich (USA). Deionized water for HPLC analysis was prepared by a Milli-Q-purification system. All other chemicals used in the study were of analytical reagent grade.

\section{Solubility of $C X B$}

The solubility of CXB in various oils (Sefsol 218, Triacetin, IPM, Labrafac, olive oil and jojoba oil), surfactants (Labrafil, Labrasol and Tween-80) and cosurfactants (Transcutol-P and Plurol oleique) was determined by dissolving an excess amount of CXB in 2 $\mathrm{mL}$ of each of the selected oils, surfactants and cosurfactants in 5-mL stoppered vials. Combinations of oils were also used for solubility determination. Excess amount of CXB was added to each 5-mL stoppered vial and mixed using a vortex mixer. The vials were then kept at $37 \pm 1.0{ }^{\circ} \mathrm{C}$ in an isothermal shaker (Nirmal International, India) for 72 hours to get to equilibrium. The equilibrated samples were removed from the shaker and centrifuged at $3000 \mathrm{rpm}$ for $15 \mathrm{~min}$. The supernatant was taken and filtered through a 0.45$-\mu \mathrm{m}$ membrane filter. The concentration of CXB was determined in each solution by HPLC at $250 \mathrm{~nm}$ (Table I).

\section{Analytical method}

CXB was analyzed by high performance liquid chromatography (HPLC) (15). Shimadzu (Japan) HPLC equipped with quaternary LC-10A VP pumps, variable wavelength 
S. Baboota et al.: Design, development and evaluation of novel nanoemulsion formulations for transdermal potential of celecoxib, Acta Pharm. 57 (2007) 315-332.

programmable UV/VIS detector SPD-10AVP, column oven, was used, SCL 10AVP system controller, Rheodyne injector fitted with a $20-\mu \mathrm{L}$ loop and Class-VP 5.032 software were used. The HPLC column used was a reverse phase $25 \times 0.46 \mathrm{~cm}$ ID SUPELCO 516 $\mathrm{C} 18 \mathrm{DB}, 5 \mu \mathrm{m}$. The whole system was kept at ambient conditions. The mobile phase was methanol/water (75:25) with the flow rate of $1.25 \mathrm{~mL} \mathrm{~min}^{-1}$. The injection volume was $20 \mu \mathrm{L}$ and the elute was analyzed at $250 \mathrm{~nm}$.

Table I. Solubility of $C X B$

\begin{tabular}{lcll}
\hline Component & $\begin{array}{c}\text { Solubility } \\
\left(\mathrm{mg} \mathrm{mL}^{-1}\right)^{\mathrm{a}}\end{array}$ & Component & $\begin{array}{c}\text { Solubility } \\
\left(\mathrm{mg} \mathrm{mL}^{-1}\right)^{\mathrm{a}}\end{array}$ \\
\hline Sefsol 218 & $77.12 \pm 0.93$ & Triacetin + IPM (1:1) & $74.13 \pm 1.84$ \\
Triacetin & $98.21 \pm 1.12$ & Triacetin + olive oil (1:1) & $69.34 \pm 1.92$ \\
IPM & $44.22 \pm 1.01$ & Triacetin + Labrafac (1:1) & $67.51 \pm 1.23$ \\
Labrafac & $26.23 \pm 0.52$ & Labrafil & $30.24 \pm 2.33$ \\
Olive oil & $36.41 \pm 0.75$ & Labrasol & $120.25 \pm 1.18$ \\
Jojoba oil & $24.33 \pm 0.82$ & Tween-80 & $150.51 \pm 1.36$ \\
Triacetin + Sefsol 218 (1:1) & $123.12 \pm 1.02$ & Transcutol-P & $125.31 \pm 1.80$ \\
Triacetin + jojoba oil (1:1) & $65.22 \pm 2.01$ & Plurol oleique & $105.26 \pm 1.25$ \\
\hline
\end{tabular}

a Mean \pm SD, $n=3$.

\section{Pseudo-ternary phase diagram}

On the basis of the solubility studies, a combination of Sefsol 218 and Triacetin (1:1) was selected as the oil phase. Tween-80 and Transcutol-P were selected as surfactant and cosurfactant, respectively. Distilled water was used as an aqueous phase. Surfactant and cosurfactant $\left(S_{\text {mix }}\right)$ were mixed at different mass ratios $(1: 0,1: 2,1: 1,2: 1,3: 1$ and 1:3). These ratios were chosen in increasing concentration of surfactant with respect to cosurfactant and increasing concentration of cosurfactant with respect to surfactant for a detailed study of the phase diagrams. For each phase diagram, oil and $S_{\text {mix }}$ at a specific ratio was mixed thoroughly at different mass ratios from 1:9 to 9:1 in different glass vials. Sixteen different combinations of oil and $S_{\text {mix }}, 1: 9,1: 8,1: 7,1: 6,1: 5,2: 8$ (1:4), 1:3.5, 1:3, 3:7 (1:2.3), 1:2, 4:6 (1:1.5), 5:5 (1:1), 6:4 (1:0.7), 7:3 (1:0.43), 8:2 (1:0.25), 9:1 (1:0.1), were made so that maximum ratios were covered for the study to delineate the boundaries of phases precisely formed in the phase diagrams. Pseudo ternary phase diagrams of oil, $\mathrm{S}_{\text {mix }}$ and aqueous phase were developed using the aqueous titration method. Slow titration with aqueous phase was performed for each mass ratio of oil and $S_{\text {mix }}$ and visual observations were made for transparent and easily flowable $\mathrm{o} / \mathrm{w}$ nanoemulsions. The physical state of the nanoemulsion was marked on a pseudo-three-component phase diagram with one axis representing the aqueous phase, the second one representing oil and the third representing a mixture of surfactant and cosurfactant at a fixed mass ratio. 
S. Baboota et al.: Design, development and evaluation of novel nanoemulsion formulations for transdermal potential of celecoxib, Acta Pharm. 57 (2007) 315-332.

\section{Selection of nanoemulsion formulation}

From each phase diagram constructed, different formulas were selected from the nanoemulsion region so that the drug could be incorporated into the oil phase. $2 \%(\mathrm{~m} / \mathrm{m})$ of $\mathrm{CXB}$, which was kept constant in all the selected formulations, was dissolved in the oil phase of nanoemulsion formulation. Selected formulations were subjected to different dispersion stability tests.

\section{Preparation of CXB gel}

CXB gel was prepared by dispersing $1 \mathrm{~g}$ of Carbopol-940 in a sufficient quantity of distilled water. After complete dispersion, the solution was kept in dark for $24 \mathrm{~h}$ for complete swelling of Carbopol-940. Then, $2 \mathrm{~g}$ of CXB was dissolved in a specified quantity of polyethylene glycol-400 (PEG-400). This drug solution was added slowly into the aqueous dispersion of Carbopol-940. Then, other ingredients such as isopropyl alcohol (IPA), propylene glycol (PG) and triethanolamine (TEA) were added to get homogeneous dispersion of the gel (Table II).

Table II. Formula for CXB gel preparation

\begin{tabular}{lc}
\hline Ingredient & Mass (g) ${ }^{\mathrm{a}}$ \\
\hline CXB & 2 \\
Carbopol-940 & 1 \\
IPA & 10 \\
PEG-400 & 10 \\
PG & 10 \\
TEA & 0.5 \\
Distilled water (q.s.) & \\
\hline
\end{tabular}

CXB - Celecoxib, IPA - isopropyl alcohol, PEG-400 polyethylene glycol-400, PG - propylene glycol, TEA - triethanolamine, a for $100 \mathrm{~g}$ of gel.

\section{Dispersion stability studies}

To overcome the problem of metastable formulation, dispersion stability tests were performed. Selected formulations were centrifuged at $3500 \mathrm{rpm}$ for $30 \mathrm{~min}$. The formulations that showed no phase separations were taken for the heating and cooling cycle. Six cycles between the refrigerator temperature $\left(4{ }^{\circ} \mathrm{C}\right)$ and $45^{\circ} \mathrm{C}$ with storage at each temperature for not less than $48 \mathrm{~h}$ were done. Those formulations which were stable at these temperatures were subjected to a freeze-thaw cycle test. Three freeze-thaw cycles were done for the formulations between -21 and $+25^{\circ} \mathrm{C}$. The formulations that survived dispersion stability tests were selected for further studies and the compositions of these formulations are given in Table III. 
S. Baboota et al.: Design, development and evaluation of novel nanoemulsion formulations for transdermal potential of celecoxib, Acta Pharm. 57 (2007) 315-332.

Table III. Composition of selected nanoemulsion formulations

\begin{tabular}{|c|c|c|c|c|c|}
\hline \multirow{2}{*}{ Code } & \multicolumn{3}{|c|}{ Component $(\% \mathrm{~m} / \mathrm{m})$} & \multirow{2}{*}{$\mathrm{Oil} / \mathrm{S}_{\text {mix }}$ ratio } & \multirow{2}{*}{$\mathrm{S}_{\text {mix }}$ (ratio) } \\
\hline & Oil & $\mathrm{S}_{\text {mix }}$ & Water & & \\
\hline $\mathrm{T} 1$ & 10 & 40 & 50 & $1: 4$ & 1:1 \\
\hline $\mathrm{T} 2$ & 10 & 50 & 40 & $1: 5$ & $1: 1$ \\
\hline T3 & 15 & 35 & 50 & $1: 2$ & $1: 1$ \\
\hline $\mathrm{T} 4$ & 15 & 45 & 40 & $1: 3$ & $1: 1$ \\
\hline T5 & 10 & 40 & 50 & $1: 4$ & $2: 1$ \\
\hline T6 & 10 & 50 & 40 & $1: 5$ & $2: 1$ \\
\hline T7 & 15 & 35 & 52 & $1: 2$ & $2: 1$ \\
\hline $\mathrm{T} 8$ & 15 & 45 & 40 & $1: 3$ & $2: 1$ \\
\hline
\end{tabular}

\section{Characterization of nanoemulsions}

The prepared nanoemulsions were characterized by the following techniques.

Transmission electron microscopy (TEM). - Morphology and structure of the nanoemulsion were studied using transmission electron microscopy TOPCON 002B operating at $200 \mathrm{KV}$ (Topcon, USA) and capable of point to point resolution. Combination of bright field imaging at increasing magnification and of diffraction modes was used to reveal the form and size of nanoemulsion droplets. In order to perform the TEM observations, a drop of the nanoemulsion was directly deposited on the holey film grid and observed after drying.

Nanoemulsion droplet size analysis. - Droplet size distribution of the nanoemulsion was determined by photon correlation spectroscopy, which analyzes the fluctuations in light scattering due to Brownian motion of the particles, using a Zetasizer 1000 HS (Malvern Instruments, UK). Light scattering was monitored at $25^{\circ} \mathrm{C}$ at a $90^{\circ}$ angle (Table IV). Droplet size distribution studies were performed at a fixed refractive index of the respective formulation.

Viscosity determination. - The viscosity of the formulations $(0.5 \mathrm{~g})$ was determined as such without dilution (Table IV) using a Brookfield DV III ultra V6.0 RV cone and plate rheometer (Brookfield Engineering Laboratories, USA) using spindle \# CPE40 at $25 \pm 0.3$ ${ }^{\circ} \mathrm{C}$. The software used for the calculations was Rheocalc V2.6.

Refractive index. - Refractive index of placebo formulations, drug-loaded formulations and one year old formulations was determined using an Abbes type refractrometer (Nirmal International) (Table V).

Solubility of CXB in optimized formulations. - The solubility of CXB was also determined in optimized nanoemulsion formulations by taking an excess amount of $\mathrm{CXB}$ in nanoemulsion formulation. The procedure used for solubility determination was the same as described in the section for CXB solubility. 
S. Baboota et al.: Design, development and evaluation of novel nanoemulsion formulations for transdermal potential of celecoxib, Acta Pharm. 57 (2007) 315-332.

Table IV. Droplet size, polydispersity and viscosity of nanoemulsion formulations

\begin{tabular}{cccc}
\hline Code & Droplet size $(\mathrm{nm})^{\mathrm{a}}$ & Polydispersity & ${\text { Viscosity }(\mathrm{mPa} s)^{\mathrm{a}}}^{\mathrm{a}}$ \\
\hline T1 & $42.91 \pm 7.16$ & 0.167 & $23.16 \pm 1.55$ \\
T2 & $34.64 \pm 3.74$ & 0.108 & $19.57 \pm 1.99$ \\
T3 & $65.83 \pm 11.25$ & 0.171 & $42.28 \pm 2.18$ \\
T4 & $61.34 \pm 10.55$ & 0.172 & $40.57 \pm 1.86$ \\
T5 & $80.61 \pm 13.30$ & 0.165 & $122.15 \pm 4.58$ \\
T6 & $73.62 \pm 11.70$ & 0.159 & $108.76 \pm 3.68$ \\
T7 & $86.81 \pm 13.45$ & 0.155 & $135.34 \pm 3.56$ \\
T8 & $81.27 \pm 13.08$ & 0.161 & $130.57 \pm 2.63$ \\
\hline
\end{tabular}

a Mean \pm SD, $n=3$.

Table V. Refractive index of nanoemulsion formulations

\begin{tabular}{cccc}
\hline \multirow{3}{*}{ Code } & \multicolumn{3}{c}{ Refractive index $^{\mathrm{a}}$} \\
\cline { 2 - 4 } & Fresh formulation & One year old formulation & Placebo formulation \\
\hline T1 & $1.404 \pm 0.006$ & $1.402 \pm 0.007$ & $1.404 \pm 0.006$ \\
T2 & $1.402 \pm 0.006$ & $1.401 \pm 0.006$ & $1.402 \pm 0.007$ \\
T3 & $1.403 \pm 0.009$ & $1.401 \pm 0.006$ & $1.403 \pm 0.092$ \\
T4 & $1.412 \pm 0.011$ & $1.401 \pm 0.008$ & $1.412 \pm 0.010$ \\
T5 & $1.404 \pm 0.010$ & $1.402 \pm 0.001$ & $1.404 \pm 0.031$ \\
T6 & $1.414 \pm 0.013$ & $1.412 \pm 0.001$ & $1.414 \pm 0.011$ \\
T7 & $1.415 \pm 0.017$ & $1.413 \pm 0.003$ & $1.415 \pm 0.003$ \\
T8 & $1.416 \pm 0.001$ & $1.413 \pm 0.002$ & $1.416 \pm 0.002$ \\
\hline
\end{tabular}

a Mean \pm SD, $n=6$.

In vitro skin permeation studies

In vitro skin permeation studies were performed on a modified Keshary Chien-diffusion cell with an effective diffusional area of $4.76 \mathrm{~cm}^{2}$ and $35 \mathrm{~mL}$ of receiver chamber capacity, using rat abdominal skin. The full thickness of rat skin was excised from the abdominal region and hairs were removed with an electric clipper. The subcutaneous tissue was removed surgically and the dermis side was wiped with isopropyl alcohol to remove adhering fat. The cleaned skin was washed with distilled water and stored at $-21{ }^{\circ} \mathrm{C}$ untill further use. The skin was brought to room temperature and mounted between the donor and receiver compartments of the Keshary-Chien diffusion cell where the stratum corneum side was facing the donor compartment and the dermal side was facing the receiver compartment. Initially, the donor compartment was empty and the receiver chamber was filled with methanolic phosphate buffer saline (PBS) pH 7.4 (30:70\%, $V / V)$. The receiver fluid was stirred with a magnetic rotor at a speed of $100 \mathrm{rpm}$ and the 
assembled apparatus was placed in a hot air oven where the temperature was maintained at $37 \pm 1{ }^{\circ} \mathrm{C}$. The whole methanolic PBS was replaced with fresh one after every $30 \mathrm{~min}$ to stabilize the skin. It was found that the receiver fluid showed a negligible peak area after $2.5 \mathrm{~h}$ and beyond indicating complete stabilization of the skin. After complete stabilization of the skin, $1 \mathrm{~mL}$ nanoemulsion formulation $\left(20 \mathrm{mg} \mathrm{mL}^{-1} \mathrm{CXB}\right)$ or $1 \mathrm{~g}$ of CXB gel $\left(20 \mathrm{mg} \mathrm{g}^{-1}\right)$ was placed into the donor compartment and sealed with paraffin film to provide occlusive conditions. Samples were withdrawn at regular intervals $(0.5$, $1,2,3,4,5,6,7,8,9,10,12,14,16$ and $24 \mathrm{~h}$ ), filtered through $0.45-\mu \mathrm{m}$ membrane filter and analyzed for drug content by HPLC at $250 \mathrm{~nm}$.

\section{Optimized formulation selection}

Formulation T2 showed the highest release compared to other nanoemulsion formulations. Thus, formulation T2 was converted into nanoemulsion gel formulation (NG2) by adding $1 \%(\mathrm{~m} / \mathrm{m})$ Carbopol-940. The skin permeation profile of nanoemulsion formulations was compared with nanoemulsion gel and $\mathrm{CXB}$ gel using the Dunnett test of one-way analysis of variance (ANOVA).

\section{Permeation data analysis}

Cumulative amount of drug permeated through the skin $\left(\mathrm{mg} \mathrm{cm}^{-2}\right)$ was plotted as a function of time for each formulation. Drug flux (permeation rate) at steady state $\left(J_{\mathrm{ss}}\right)$ was calculated by dividing the slope of the graph linear portion with the diffusion cell area $\left(\mathrm{mg} \mathrm{cm}^{-2} \mathrm{~h}^{-1}\right)(4,5)$. Permeability coefficient $\left(K_{\mathrm{p}}\right)$ was calculated by dividing $J_{\mathrm{ss}}$ by the initial concentration of the drug in the donor cell $\left(\mathrm{cm} \mathrm{h}^{-1}\right)(4,5)$.

Enhancement ratio $\left(E_{\mathrm{r}}\right)$ was calculated by dividing $J_{\mathrm{SS}}$ of the respective formulation by $J_{\mathrm{SS}}$ of the control formulation $(4,5)$. The mean values of these parameters are given in Table VI.

Table VI. Permeability parameters of different formulations

\begin{tabular}{cccc}
\hline Code & $J_{\mathrm{ss}}\left(\mathrm{mg} \mathrm{cm}^{-2} \mathrm{~h}^{-1}\right)^{\mathrm{b}}$ & $K_{\mathrm{p}} \times 10^{-2}\left(\mathrm{~cm} \mathrm{~h}^{-1}\right)^{\mathrm{b}}$ & $E_{\mathrm{r}}$ \\
\hline Control $^{\mathrm{a}}$ & $0.031 \pm 0.011$ & $0.156 \pm 0.101$ & - \\
$\mathrm{T} 1$ & $0.143 \pm 0.085$ & $0.717 \pm 0.140$ & 4.58 \\
$\mathrm{~T} 2$ & $0.147 \pm 0.065$ & $0.736 \pm 0.150$ & 4.70 \\
$\mathrm{~T} 3$ & $0.103 \pm 0.087$ & $0.515 \pm 0.110$ & 3.31 \\
$\mathrm{~T} 4$ & $0.120 \pm 0.010$ & $0.603 \pm 0.160$ & 3.85 \\
$\mathrm{~T} 5$ & $0.113 \pm 0.120$ & $0.567 \pm 0.140$ & 3.62 \\
$\mathrm{~T} 6$ & $0.117 \pm 0.140$ & $0.585 \pm 0.170$ & 3.73 \\
$\mathrm{~T} 7$ & $0.094 \pm 0.051$ & $0.471 \pm 0.170$ & 3.00 \\
$\mathrm{~T} 8$ & $0.106 \pm 0.054$ & $0.534 \pm 0.190$ & 3.41 \\
$\mathrm{NG} 2$ & $0.114 \pm 0.053$ & $0.571 \pm 0.201$ & 3.65 \\
\hline
\end{tabular}

a CXB gel was used as control.

b Mean $\pm \mathrm{SD}, n=3$.

$J_{\mathrm{ss}}$ - steady state flux, $K_{\mathrm{p}}$ - permeability coefficient, $E_{\mathrm{r}}$ - enhancement ratio. 
S. Baboota et al.: Design, development and evaluation of novel nanoemulsion formulations for transdermal potential of celecoxib, Acta Pharm. 57 (2007) 315-332.

Table VII. Anti-inflammatory effects of T1, T2, NG2 and CXB gel

\begin{tabular}{|c|c|c|c|c|c|c|}
\hline Group & Formulation & $\mathrm{N}$ & $\begin{array}{c}\text { Mean mass in } \\
\text { a group }(g)^{a}\end{array}$ & Time (h) & $\begin{array}{c}\text { Edema } \\
(\text { mean } \pm \text { SD, \% })^{a}\end{array}$ & $\begin{array}{l}\text { Inhibition } \\
\qquad(\%)\end{array}$ \\
\hline \multirow{6}{*}{ I } & \multirow{6}{*}{$\begin{array}{c}\text { Control } \\
\text { (carrageenean } \\
\text { only) }\end{array}$} & \multirow{6}{*}{6} & \multirow{6}{*}{$190 \pm 10$} & 1 & $32.0 \pm 1.2$ & \multirow{6}{*}{-} \\
\hline & & & & 2 & $46.0 \pm 1.3$ & \\
\hline & & & & 3 & $81.0 \pm 1.2$ & \\
\hline & & & & 6 & $51.0 \pm 1.5$ & \\
\hline & & & & 12 & $43.0 \pm 1.5$ & \\
\hline & & & & 24 & $15.0 \pm 1.3$ & \\
\hline \multirow{6}{*}{ II } & \multirow{6}{*}{$\mathrm{T} 1$} & \multirow{6}{*}{6} & \multirow{6}{*}{$200 \pm 13$} & 1 & $24.0 \pm 1.0$ & 25 \\
\hline & & & & 2 & $31.78 \pm 1.4$ & 31 \\
\hline & & & & 3 & $48.6 \pm 1.5$ & 40 \\
\hline & & & & 6 & $23.3 \pm 2.0$ & 54 \\
\hline & & & & 12 & $16.2 \pm 2.2$ & 62 \\
\hline & & & & 24 & $4.3 \pm 2.2$ & 71 \\
\hline \multirow{6}{*}{ III } & \multirow{6}{*}{$\mathrm{T} 2$} & \multirow{6}{*}{6} & \multirow{6}{*}{$180 \pm 11$} & 1 & $21.0 \pm 1.0$ & 34 \\
\hline & & & & 2 & $29.1 \pm 1.3$ & 37 \\
\hline & & & & 3 & $46.9 \pm 1.4$ & 42 \\
\hline & & & & 6 & $20.1 \pm 1.5$ & 61 \\
\hline & & & & 12 & $12.6 \pm 1.7$ & 71 \\
\hline & & & & 24 & $2.8 \pm 1.8$ & 81 \\
\hline \multirow{6}{*}{ IV } & \multirow{6}{*}{ NG2 } & \multirow{6}{*}{6} & \multirow{6}{*}{$200 \pm 14$} & 1 & $26.0 \pm 1.1$ & 19 \\
\hline & & & & 2 & $33.0 \pm 1.2$ & 28 \\
\hline & & & & 3 & $36.7 \pm 1.4$ & 55 \\
\hline & & & & 6 & $20.1 \pm 2.2$ & 61 \\
\hline & & & & 12 & $15.6 \pm 2.3$ & 64 \\
\hline & & & & 24 & $5.3 \pm 2.5$ & 65 \\
\hline \multirow{6}{*}{ V } & \multirow{6}{*}{ CXB gel } & \multirow{6}{*}{6} & \multirow{6}{*}{$220 \pm 16$} & 1 & $29.0 \pm 1.1$ & 9 \\
\hline & & & & 2 & $41.4 \pm 1.3$ & 10 \\
\hline & & & & 3 & $56.2 \pm 1.5$ & 31 \\
\hline & & & & 6 & $37.7 \pm 2.1$ & 26 \\
\hline & & & & 12 & $25.3 \pm 2.2$ & 41 \\
\hline & & & & 24 & $8.4 \pm 2.4$ & 44 \\
\hline
\end{tabular}

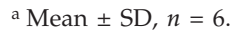

\section{Skin irritancy test}

Skin irritancy test was done on male Swiss albino mice, weighing 25-30 g. The animals were kept under standard laboratory conditions, temperature $\left(25 \pm 1^{\circ} \mathrm{C}\right)$ and relative humidity $(55 \pm 5 \%)$. The animals were housed in polypropylene cages, six per cage, with free access to standard laboratory diet (Lipton Feed, India) and water ad libitum. A single dose of $10 \mu \mathrm{L}$ of the nanoemulsion was applied to the left ear of the mice, with the right ear as a control. The development of erythema was monitored for 6 days using the reported method (16). 
S. Baboota et al.: Design, development and evaluation of novel nanoemulsion formulations for transdermal potential of celecoxib, Acta Pharm. 57 (2007) 315-332.

\section{In vivo studies}

Approval to carry out in vivo studies was obtained from the Institutional Animal Ethics Committee, Jamia Hamdard, New Delhi, India, and their guidelines were followed throughout the studies. The anti-inflammatory and sustaining actions of the optimized formulations were evaluated by the carrageenean-induced hind paw edema method developed by Winter et al. (17) in Wistar rats. Young male Wistar rats, weighing 180-220 g, were randomly divided into 5 groups: control, T1, T2, NG2 and CXB gel, each containing 6 rats. The animals were kept under standard laboratory conditions, temperature at $25 \pm 1{ }^{\circ} \mathrm{C}$ and relative humidity $(55 \pm 5 \%)$. The animals were housed in polypropylene cages, six per cage, with free access to standard laboratory diet (Lipton Feed) and water ad libitum. Doses for the rats were calculated based on the mass of the animals according to the surface area ratio (18). The abdominal region of the rats was shaved $12 \mathrm{~h}$ before starting the experiments, except in the control group. Nanoemulsions, nanoemulsion gel and $\mathrm{CXB}$ gel formulations were applied on the shaved abdominal region of all animals (except in the control group) half an hour before subplanter injection of carrageenean into right paws. Paw edema was induced by injecting $0.1 \mathrm{~mL}$ of $1 \%(\mathrm{~m} / \mathrm{m})$ homogeneous suspension of carrageenean in distilled water. The paw volume was measured at 1, 2, 3, 6, 12 and $24 \mathrm{~h}$ after injection using a digital plethysmometer. The amount of paw swelling was determined from time to time and expressed as percent edema relative to the initial hind paw volume. Percent inhibition of edema produced by each formulation-treated group was calculated against the respective control group. Results of anti-inflammatory activity were compared using the Dunnett test of one-way analysis of variance (ANOVA).

\section{RESULTS AND DISCUSSION}

The physicochemical properties of CXB suggest that it has good potential for topical drug delivery (2). The important criterion for selection of materials for the nanoemulsion formulation development is that the components are pharmaceutically acceptable, nonirritant and nonsensitizing to the skin and fall under the GRAS (Generally Regarded as Safe) category. Non-ionic surfactants are less toxic than ionic surfactants. The higher solubility of the drug in the oil phase is important for the nanoemulsion to maintain the drug in solubilized form. The right blend of low and high hydrophilic lipophilic balance (HLB) surfactants leads to the formation of a stable nanoemulsion formulation (19). In this study, we selected Tween 80 as a surfactant having the HLB value 15 . Transient negative interfacial tension and fluid interfacial film is rarely achieved by the use of a single surfactant, usually necessitating addition of a co-surfactant. The presence of co-surfactant decreases the bending stress of the interface and allows the interfacial film sufficient flexibility to take up different curvatures required to form a nanoemulsion over a wide range of compositions (20). Thus, the co-surfactant selected for the study was Transcutol-P with the HLB value of 4.2 .

Therefore, the aim of the present study was to develop and evaluate thermodynamically stable $\mathrm{o} / \mathrm{w}$ nanoemulsions of $\mathrm{CXB}$ for transdermal drug delivery. These nanoemulsions were prepared by using a combination of Sefsol 218 and Triacetin as the oil phase, 
Tween-80 and Transcutol-p as surfactant and cosurfactant, respectively. All these chemicals are nonirritant and nonsensitizing to the skin, fall under the GRAS category and are pharmaceutically acceptable.

The most important criterion for screening of components is the solubility of a poorly soluble drug in oil, surfactants and cosurfactants. Since the aim of this study is to develop a transdermal formulation, it is important to determine drug solubility in oils, surfactants and cosurfactants. The solubility of CXB was found to be highest in a 1:1 combination of Sefsol 218 and Triacetin (123.12 $\left.\pm 1.02 \mathrm{mg} \mathrm{mL}^{-1}\right)$ as compared to other oils and combinations of oils. Hence, this combination was selected as the oil phase for the development of optimal formulation. High drug solubility was found in Tween 80 and Transcutol-P. Therefore, Tween- 80 and Transcutol-P were selected as surfactant and cosurfactant, respectively, for the phase study (Table I).

\section{Pseudo-ternary phase diagram}

Care was taken to ensure that observations were not made on metastable systems; although the free energy required to form an emulsion is very low, the formation is thermodynamically spontaneous (19). The relationship between the phase behaviour of a mixture and its composition can be captured with the aid of a phase diagram (21). Pseudoternary phase diagrams were constructed separately for each $S_{\text {mix }}$ ratio (Fig. 1), so that $\mathrm{o} / \mathrm{w}$ nanoemulsion regions could be identified and nanoemulsion formulations could be optimized.

In Fig. 1a, $\mathrm{S}_{\text {mix }}$ with a ratio 1:0 showed large nanoemulsion area. $\mathrm{O} / \mathrm{w}$ nanoemulsion region was found towards the water rich apex of the phase diagram and in higher concentration of $S_{\mathrm{mix}}$, showing that Tween 80 could be used alone without cosurfactant, but a higher concentration of surfactant would be required. The maximum concentration of oil that could be solubilized in the phase diagram was nearly $25 \%(\mathrm{~m} / \mathrm{m})$ using around $50 \%(\mathrm{~m} / \mathrm{m})$ of $S_{\text {mix }}$. It was observed in 1:2 $S_{\text {mix }}$ (Fig. 1b) that when cosurfactant was added along with surfactant, the interfacial film became more fluid and no liquid crystalline area was found in the phase diagram. A large o/w nanoemulsion area was observed. The maximum amount of oil that could be solubilized was $28 \%(\mathrm{~m} / \mathrm{m})$ with around $41 \%(\mathrm{~m} / \mathrm{m})$ of $\mathrm{S}_{\text {mix }}$. As the surfactant concentration was increased in $\mathrm{S}_{\text {mix }}$ (ratio 1:1, Fig. 1c), a higher nanoemulsion region was observed. It may be due to further reduction of the interfacial tension, increasing the fluidity of the interface, thereby increasing the entropy of the system. There may be greater penetration of the oil phase in the hydrophobic region of the surfactant monomers $(21,22)$. As we further increased surfactant concentration in $S_{\text {mix }}$ to 2:1 (Fig. 1d), the nanoemulsion region decreased as compared to $1: 1$, the maximum concentration of oil that could be solubilized by this ratio was $28 \%(\mathrm{~m} / \mathrm{m})$ utilizing $41 \%(\mathrm{~m} / \mathrm{m})$ of $\mathrm{S}_{\text {mix }}$. When the $\mathrm{S}_{\text {mix }}$ ratio of $3: 1$ was studied (Fig. $1 \mathrm{e})$, the small area of nanooemulsion further decreased and the liquid crystalline area started to appear in the phase diagram, which may be due to increased surfactant concentration. The maximum concentration of oil that could be solubilized with $41 \%$ of $S_{\text {mix }}$ was $28 \%$. When cosurfactant concentration was increased from 1:1 to 1:2 compared to surfactant, the nanoemulsion area decreased.

It is well known that large amounts of surfactants cause skin irritation $(21,23)$, it is therefore important to determine the surfactant concentration properly and use the opti- 
S. Baboota et al.: Design, development and evaluation of novel nanoemulsion formulations for transdermal potential of celecoxib, Acta Pharm. 57 (2007) 315-332.

a)

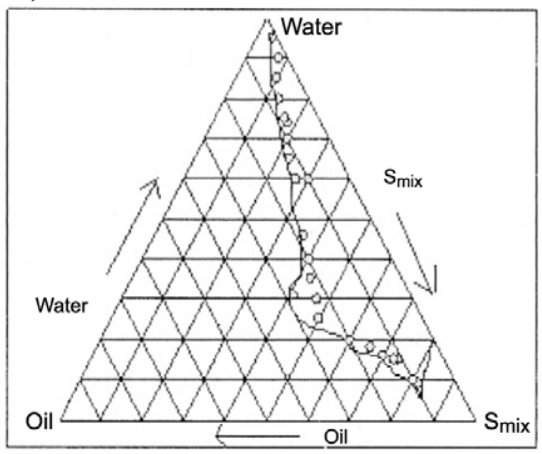

c)

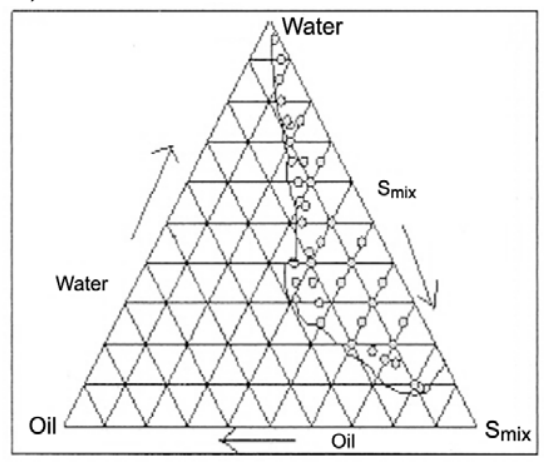

e)

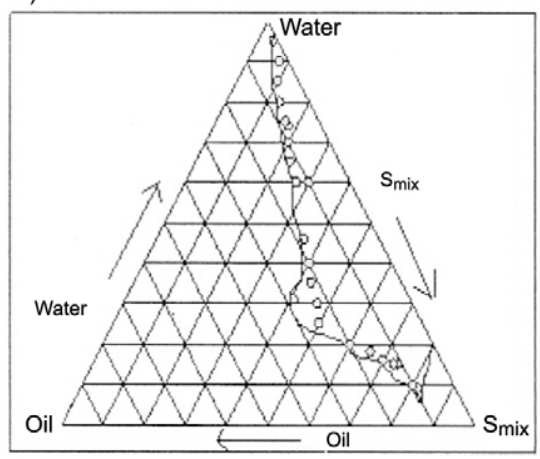

b)

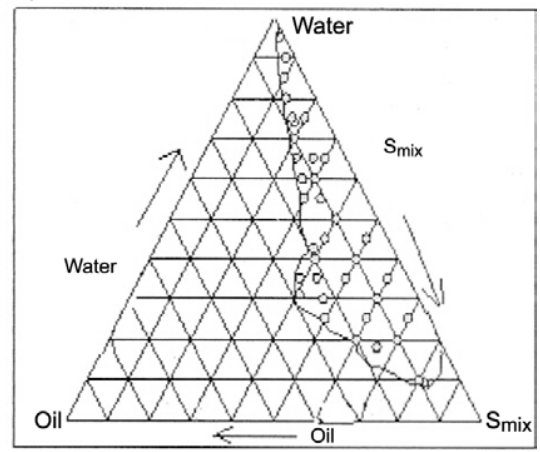

d)

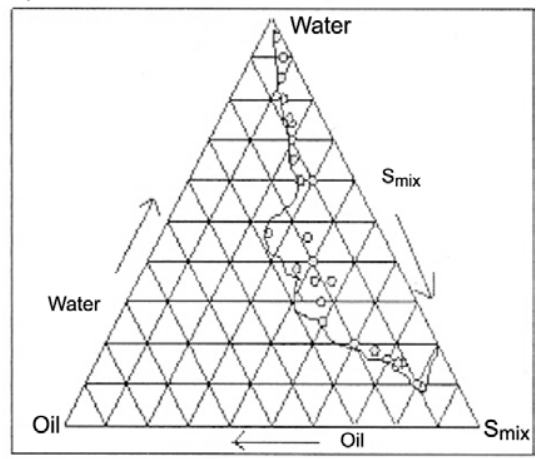

Fig. 1. Pseudo-ternary phase diagrams showing the $\mathrm{o} / \mathrm{w}$ nanoemulsion (shaded area) regions of Sefsol 218 and Triacetin (oil), Tween-80 (surfactant), Transcutol-P (cosurfactant) at different $S_{\text {mix }}$ ratios: a) $S_{\text {mix }}$ $1: 0$, b) $S_{\text {mix }} 1: 2$, c) $S_{\text {mix }} 1: 1$, d) $S_{\text {mix }} 2: 1$ and e) $S_{\operatorname{mix}} 3: 1$.

mum concentration of surfactant in the formulation. From pseudoternary phase diagrams, the formulations in which the amount of oil phase completely solubilized the drug and which could accommodate the optimum quantity of $S_{\text {mix }}$ and distilled water were selected for the study. 
S. Baboota et al.: Design, development and evaluation of novel nanoemulsion formulations for transdermal potential of celecoxib, Acta Pharm. 57 (2007) 315-332.

\section{Dispersion stability studies}

Nanoemulsions are thermodynamically and physically stable systems and are formed at a particular concentration of oil, surfactant and water, making them stable to phase separation, creaming or cracking $(6,7)$. It is the thermostability that differentiates nanoemulsion from emulsions with kinetic stability and eventually phase separation $(21,24)$. Thus, the formulations were tested for their physical (dispersion) stability by using centrifugation, heating-cooling cycle and freeze-thaw cycle. Only those formulations which survived dispersion stability tests, were selected for further study. The compositions of selected formulations are given in Table III.

\section{Characterization of nanoemulsions}

Transmission electron microscopy. - The nanoemulsion appeared dark and with bright surroundings and a positive image (Fig. 2). The droplet size ranged between 19 and 78 $\mathrm{nm}$ and was in agreement with the droplet size distribution measured using photon correlation spectroscopy (Table IV).

Nanoemulsion droplet size analysis. - The droplet size increased with the increase in oil concentration in the formulations (Table IV). The droplet size of formulation T2, containing $10 \%$ of oil was $34.6 \pm 1.0 \mathrm{~nm}$, which was lower as compared to other formulations. There was only a marginal difference in the mean droplet size of formulations T1 and T2, which may be due to the increase in the concentration of $S_{\operatorname{mix}}$ in T2. This result is in accordance with the report that the addition of surfactant to nanoemulsion systems causes the interfacial film to condense and stabilize, while the cosurfactant causes the film to expand (25). All the formulations had droplets in the nano range which is well

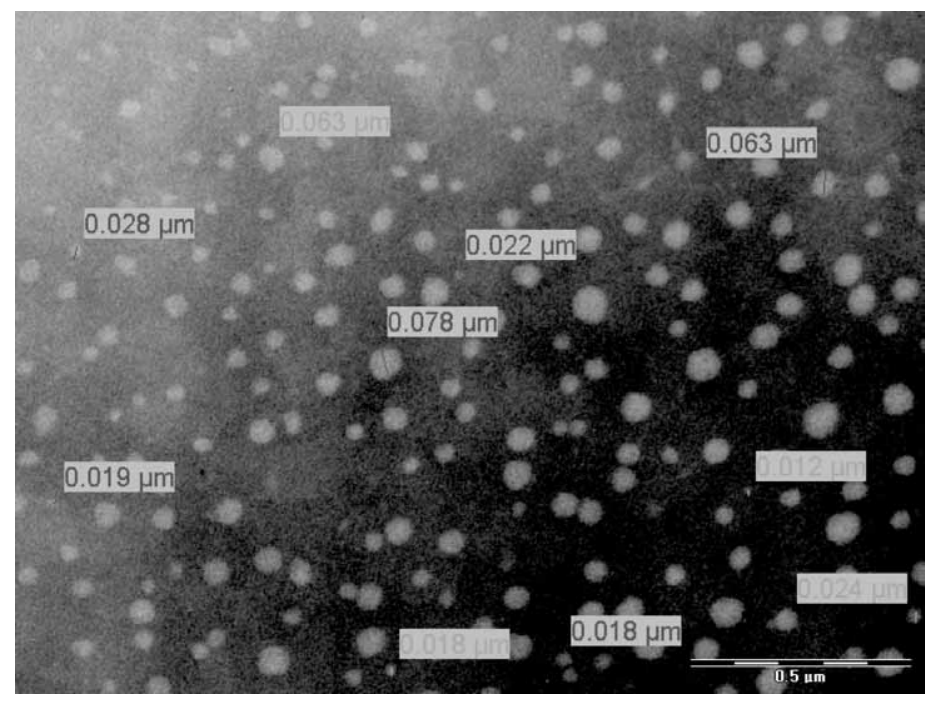

Fig. 2. Transmission electron microscopic positive image of CXB nanoemulsion. 
S. Baboota et al.: Design, development and evaluation of novel nanoemulsion formulations for transdermal potential of celecoxib, Acta Pharm. 57 (2007) 315-332.

evident from the low values of polydispersity. Polydispersity is basically the ratio of standard deviation to the mean droplet size. This signifies the uniformity of droplet size within the formulation. The higher the value of polydispersity, the lower is the uniformity of the droplet size in the formulation. The polydispersity values of the formulations are very low $(0.108-0.172)$ which indicates uniformity of droplet size within the formulation.

Viscosity and refractive index. - Formulation T2 had the least viscosity $(19.57 \pm 1.99$ $\mathrm{mPa}$ s) compared to other formulations (Table IV). This may be due to the lower oil content. The difference in viscosity between formulations T1 and T2 was not significant; viscosity of all nanoemulsion formulations was very low as expected (21).

There was no significant change in the mean values of the refractive index of selected formulations, placebo formulations and one year old formulations. Thus, it can be concluded that the nanoemulsion formulations were not only physically stable but also chemically stable and remained isotropic in nature, without interactions between nanoemulsion components and drug (Table V).

Solubility of optimized formulations. - The solubility of CXB in optimized formulations T1 and T2 was determined and compared with aqueous solubility of CXB. Significant increase in solubility of CXB in nanoemulsion formulations T1 (42000 fold) and T2 (44000 fold) was found as compared to water, which could be due to the presence of surfactant (Tween-80) and cosurfactant (Transcutol-P) $(p<0.01)$, thus indicated the enhanced permeability of CXB through the skin.

\section{In vitro skin permeation studies}

In vitro skin permeation studies were performed to compare the drug release from eight different nanoemulsion formulations (T1 to T8), nanoemulsion gel (NG2) and CXB gel, all having the same quantity $(2 \%, \mathrm{~m} / \mathrm{m})$ of CXB. The solubility of CXB in PBS is only $9 \mu \mathrm{g} \mathrm{mL}^{-1}$; therefore $30 \%(V / V)$ methanol was added into receiver compartment to increase CXB solubility to $10 \mu \mathrm{g} \mathrm{mL}^{-1}$. This was done in order to maintain the sink condition. In vitro skin permeation was the highest in formulations T1 and T2 and the lowest for CXB gel (Fig. 3). Formulation NG2 showed an intermediate skin permeation profile. The skin permeation profiles of T1 and T2 were not significantly different but they were significantly different from simple gel and NG2 $(p<0.05)$. The significant difference in CXB permeation between nanoemulsion formulations, NG2 and CXB gel was probably due to the mean size of internal phase droplets, which were significantly smaller in nanoemulsions. The maximum release in $\mathrm{T} 1$ and $\mathrm{T} 2$ could be due to the smallest droplet size and lowest viscosity compared to nanoemulsions T3 to T8. To explain the probable mechanism by which nanoemulsions enhance the skin permeation of drugs, the histological and histochemical structure of stratum corneum must be taken into consideration. Drugs permeate stratum corneum through two micro pathways, i.e., intercellular and transcellular pathways. Of these, the intercellular pathway plays a major role in percutaneous uptake of drugs. It is well known that a complex mixture of essentially neutral lipids, which are arranged as a bilayer with their hydrophobic chains facing each others, forms a lipophilic bimolecular leaflet. Most of the lipophilic drugs pass through this region, and it is called a lipid pathway. The polar head group of lipids faces an aqueous region, forming a polar route that hydrophilic drugs generally prefer. A dermally applied 
S. Baboota et al.: Design, development and evaluation of novel nanoemulsion formulations for transdermal potential of celecoxib, Acta Pharm. 57 (2007) 315-332.
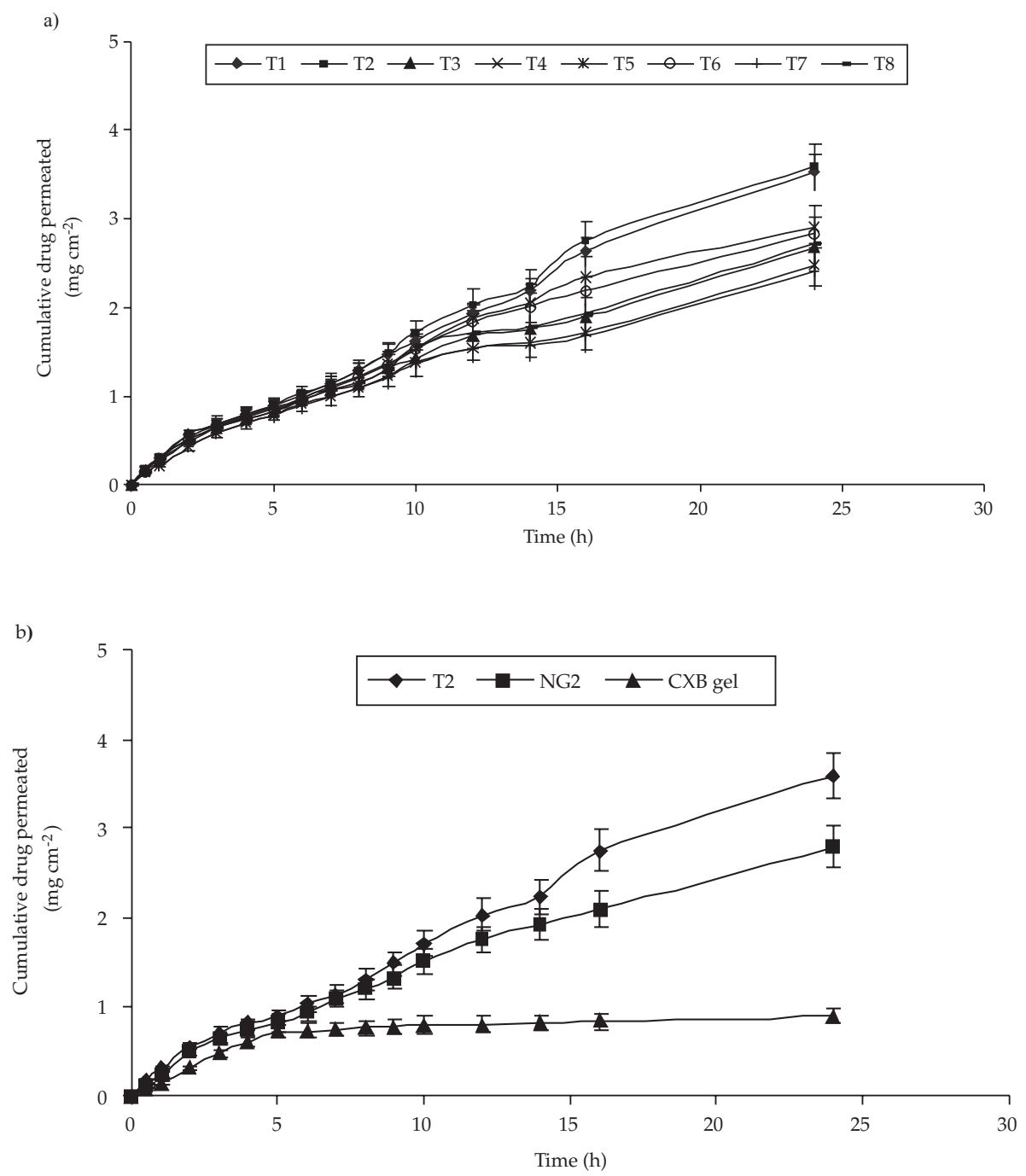

Fig. 3. In vitro skin permeation profile of $\mathrm{CXB}$ (mean $\pm \mathrm{SD}, n=3$ ) from: a) formulations $\mathrm{T} 1$ to $\mathrm{T} 8, \mathrm{~b}) \mathrm{T} 2, \mathrm{NG} 2$ and $\mathrm{CXB}$ gel.

nanoemulsion is expected to penetrate the stratum corneum and to exist intact in the whole horney layer, alter both lipid and polar pathways (26). The drug dissolved in the lipid domain of the nanoemulsions can directly penetrate the lipid of the stratum corneum, thereby destabilizing its bilayer structure. These interactions will increase the lipid pathway permeability to drugs. On the other hand, the hydrophilic domain of nanoemulsions can hydrate the stratum corneum to a greater extent and play an important 
role in percutaneous uptake of drugs. When the aqueous fluid of nanoemulsions enters the polar pathway, it increases the interlamellar volume of the stratum corneum lipid bilayer, resulting in disruption of its interfacial structure. A lipophilic drug like CXB can then permeate more easily through the lipid pathway of stratum corneum. Moreover, droplet size and viscosity of the nanoemulsion may also affect its efficiency, where the small droplet size and low viscosity of the nanoemulsion make it an excellent carrier for enhancing percutaneous uptake of $\mathrm{CXB}$, since the number of vesicles that can interact on a fixed area of stratum corneum will increase when droplet size and viscosity decrease. Therefore, the probable reason for enhanced permeation of CXB from T1 and T2 could be the combined effects of hydrophilic and lipophilic domains as well as the smallest droplet size and lowest viscosity of nanoemulsions.

Permeability parameters like steady state flux $\left(J_{\mathrm{ss}}\right)$, permeability coefficient $\left(K_{\mathrm{p}}\right)$ and enhancement ratio $\left(E_{\mathrm{r}}\right)$ significantly increased in nanoemulsions and NG2 formulation compared to CXB gel $(p<0.05)$. This is because nanoemulsions and NG2 components contain permeation enhancers like Sefsol 218, Triacetin, Tween-80 and Transcutol-p. The permeability parameters of different formulations are given in Table VI.

\section{In vivo studies}

Based on higher drug release, optimum droplet size, lower viscosity and lowest polydispersibility index, formulations T1 and T2 were selected for the in vivo anti-inflammatory effects. The percent inhibition value after $24 \mathrm{~h}$ administration was found to be high for T2, i.e., $81.2 \%$ as compared to CXB gel $(43.7 \%)$; this difference was significant $(p<0.01)$. The percent inhibition value for formulations T1 and NG2 was found to be $70.8 \%$ and $64.5 \%$, respectively (Table VII); the difference was significant $(p<0.05)$ when compared formulation T2. The enhanced anti-inflammatory effects of formulation T2 could be due to the enhanced permeation of CXB through the skin.

Based on higher drug permeation, smallest droplet size, minimum polydispersity, lower viscosity, optimum surfactant and cosurfactant concentration and higher solubility, formulation T2 was optimized as the nanoemulsion formulation of celecoxib.

The skin irritancy test was performed to confirm the safety of the optimized nanoemulsion formulation. Van Abbe et al. (16) mentioned that a value of skin irritancy score between 0 and 9 indicates that the applied formulation is not irritant to human skin. The mean value of skin irritancy score for formulation T2 was found to be $1.3 \pm 0.3$. From this value, it was concluded that the optimized nanoemulsion formulation was safe for transdermal drug delivery.

\section{CONCLUSIONS}

The nanoemulsion formulation of celecoxib containing $2 \%(\mathrm{~m} / \mathrm{m})$ of CXB, $10 \%(\mathrm{~m} / \mathrm{m})$ of oil phase (Sefsol 218 and Triacetin), 50\% $(\mathrm{m} / \mathrm{m})$ of surfactant mixture (Tween-80 and Transcutol-P) and $40 \%(\mathrm{~m} / \mathrm{m})$ of distilled water has been optimized. From in vitro and in vivo data it can be concluded that the developed nanoemulsions have great potential for transdermal drug delivery. 
S. Baboota et al.: Design, development and evaluation of novel nanoemulsion formulations for transdermal potential of celecoxib, Acta Pharm. 57 (2007) 315-332.

Acknowledgements. - The authors are grateful to the University Grant Commission (UGC), New Delhi, India, for providing financial support for this project. The authors also thank to Gattefossé, France, for providing the gift samples of oils, surfactants and cosurfactants.

\section{REFERENCES}

1. E. Escibano, A. C. Calpena, J. Queralt, R. Obach and J. Domenech, Assessment of diclofenac permeation with different formulations: anti-inflammatory study of a selected formula, Eur. J. Pharm. Sci. 19 (2003) 203-210; DOI: 10.1016/S0928-0987(03)00103-9.

2. Gaurel, A. M. Martel and J. Castaner, Celecoxib, anti-inflammatory, cyclo-oxygenase-2 inhibitor, Drug Future 22 (1997) 711-714.

3. K. A. Walters, Penetration Enhancers and their Use in Transdermal Therapeutic Systems, in Transdermal Drug Delivery: Developmental Issues and Research Initiatives (Eds. J. Hadgraft and R. H. Guy), Marcel Dekker, New York 1989, pp. 197-246.

4. D. W. Osborne, A. J. Ward and K. J. Neil, Microemulsions as topical delivery vehicles: in-vitro transdermal studies of a model hydrophilic drug, J. Pharm. Phamacol. 43 (1991) 450-454.

5. M. Trotta, F. Pattarino and M. R. Gasco, Influence of counter ions on the skin permeation of methotrexate from water-oil microemulsions, Pharm. Acta. Helv. 71 (1996) 135-140; DOI: 10.1016/ 0031-6865(96)00003-9.

6. S. Shafiq, S. Faiyaz, T. Sushma, J. A. Farhan, R. K. Khar and M. Ali, Design and development of ramipril nanoemulsion formulation: In vitro and in vivo assessment, J. Biomed. Nanotechnol. 3 (2007) 28-44; DOI: 10.1166/jbn.2007.008.

7. S. Shafiq, S. Faiyaz, T. Sushma, J. A. Farhan, R. K. Khar and M. Ali, Development and bioavailability assessment of ramipril nanoemulsion formulation, Eur. J. Pharm. Biopharm. 66 (2007) 227243; DOI: org/10.1016/j.ejpb.2006.10.014.

8. M. B. Delgado-Charro, G. Iglesias-Vilas, J. Blanco-Mendez, M. J. Lopez-Quintela, M. A. Marty and J. P. Guy, Delivery of a hydrophilic solute through the skin from novel microemulsion systems, Eur. J. Pharm. Biopharm. 43 (1997) 37-42; DOI: 10.1016/S0939-6411(96)00016-1.

9. M. Kreilgaard, E. J. Pedersen and J. W. Jaroszewski, NMR characterization and transdermal drug delivery potentials of microemulsion systems, J. Control. Rel. 69 (2000) 421-433; DOI: 10.1016/ S0168-3659(00)00325-4.

10. P. J. Lee, R. Langer and V. P. Shastri, Novel microemulsion enhancer formulation for simultaneous transdermal delivery of hydrophilic and hydrophobic drugs, Pharm. Res. 20 (2003) 264-269; DOI: 10.1023 / A:1022283423116.

11. M. Kreilgaard, Dermal pharmacokinetics of microemulsion formulations determined by in-vitro microdialysis, Pharm. Res. 18 (2001) 367-373; DOI: $10.1023 /$ A:1011067300397.

12. M. Kreilgaard, M. J. B. Kemme, J. Burggraaf, R. C. Schoemaker and A. F. Cohen, Influence of a microemulsion vehicle on cutaneous bioequivalence of a lipophilic model drug assessed by microdialysis and pharmacodynamics, Pharm. Res. 18 (2001) 593-599; DOI: 10.1023/A:1011068907416.

13. M. R. Gasco, M. Gallarate and F. Pattarino, In-vitro permeation of zelaic acid from viscosized microemulsions, Int. J. Pharm. 69 (1991) 193-196; DOI: 10.1016/0378-5173(91)90361-Q.

14. K. Kriwet and C. C. Muller-Goymann, Diclofenac release from phospholipids drug systems and permeation through excised human stratum corneum, Int. J. Pharm. 125 (1995) 231-242; DOI: 10.1016/0378-5173(95)00130-B.

15. S. Baboota, F. Shakeel, A. Ahuja, J. Ali, S. Shafiq and S. Ahmed, Development and validation of stability indicating HPLC method for analysis of Celecoxib in bulk drug and microemulsion formulations, Acta Chromat. (in press). 
S. Baboota et al.: Design, development and evaluation of novel nanoemulsion formulations for transdermal potential of celecoxib, Acta Pharm. 57 (2007) 315-332.

16. N. J. Van Abbe, P. Nicholas and E. Boon, Exaggerated exposure in topical irritancy and sensitization testing, J. Soc. Cosmet. Chem. 26 (1975) 173-187.

17. C. A. Winter, Anti-inflammatory testing methods: Comparative evaluation of indomethacin and other agents, NSAID, 82 (1965) 190-202.

18. M. N. Gosh, Fundamentals of Experimental Pharmacology, $3^{\text {rd }}$ ed., Hilton and Co., Kolkata 2005, p. 192.

19. D. Q. M. Craig, S. A. Barker, D. Banning and S. W. Booth, An investigation into the mechanisms of self-emulsification using particle size analysis and low frequency dielectric spectroscopy, Int. J. Pharm. 114 (1995) 103-110; DOI: 10.1016/0378-5173(94)00222-Q.

20. K. Kawakami, T. Yoshikawa, Y. Moroto, E. Kanaoka, K. Takahashi, Y. Nishihara and K. Masuda, Microemulsion formulation for enhanced absorption of poorly soluble drugs I. Prescription design, J. Control. Rel. 81 (2002) 65-74; DOI: 10.1016/S0168-3659(02)00049-4.

21. M. J. Lawrence and G. D. Rees, Microemulsion-based media as novel drug delivery systems, Adv. Drug Deliv. Rev. 45 (2000) 89-121; DOI: 10.1016/S0169-409X(00)00103-4.

22. W. Warisnoicharoen, A. B. Lansley and M. J. Lawrence, Light scattering investigations on dilute non-ionic oil-in-water microemulsions, AAPS PharmSci. 2 (2000) article 12; DOI: 10.1208/ps020212.

23. L. Ping, A. Ghosh, R. F. Wagner, S. Krill, Y. M. Joshi and A. T. M. Serajuddin, Effect of combined use of nonionic surfactant on formation of oil-in-water microemulsions, Int. J. Pharm. 288 (2005) 27-34; DOI: 10.1016/jijpharm.2004.08.024.

24. K. Shinoda and H. Kunieda, Phase Properties of Emulsions: PIT and HLB, in Encyclopedia of Emulsion Technolog (Eds. K. Shinoda and H. H. Kunieda), Marcel Dekker, New York 1983, pp. 337367.

25. N. J. Kale and A. V. Allen, Studies on microemulsions using Brij-96 as surfactant and glycerin, ethylene glycol and propylene glycol as cosurfactants, Int. J. Pharm. 57 (1998) 87-93; DOI: 10. 1016/0378-5173(89)90296-2.

26. D. Thacrodi and R. K. Panduranga, Transdermal absorption of nifedipine from microemulsions of lipophilic skin penetration enhancers, Int. J. Pharm. 111 (1994) 235-240; DOI: 10.1016/03785173(94)90346-8.

\author{
$S A \check{Z} E T A K$
}

\title{
Dizajn, razvoj i vrednovanje novih nanoemulzija za transdermalnu primjenu celekoksiba
}

SANJULA BABOOTA, FAIYAZ SHAKEEL, ALKA AHUJA, JAVED ALI i SHEIKH SHAFIQ

U radu su opisana ispitivanja nanoemulzija za transdermalnu primjenu celekoksiba (CXB). Profil permeacije kroz kožu ispitivan je in vitro i uspoređivan sa CXB gelom i nanoemulzijskim gelom. U formulacijama T1 i T2 postignuto je značajno povećanje ustaljenog fluksa $\left(J_{\mathrm{ss}}\right)$, koeficijenta permeabilnosti $\left(K_{\mathrm{p}}\right)$ i povećanje omjera $\left(E_{\mathrm{r}}\right)(p<0.05)$. Najveće vrijednosti parametara permeabilnosti dobivene su u formulaciji T2 koja je sadržala $2 \% \mathrm{~m} / \mathrm{m}$ CXB, $10 \% \mathrm{~m} / \mathrm{m}$ uljne faze (Sefsol 218 i Triacetin), $50 \% \mathrm{~m} / \mathrm{m}$ površinski-aktivnih tvari (Tween-80 i Transcutol-P) i 40\% $\mathrm{m} / \mathrm{m}$ vode. Protuupalno djelovanje formulacije T2 na edem šape štakora uzrokovan karageninom značajno je povećano $(p<0.05)$ poslije 24 $\mathrm{h}$ u usporedbi sa CXB gelom i nanoemulzijskim gelom. Rezultati ukazuju na poboljšanu isporuku celekoksiba putem nanoemulzija. 
S. Baboota et al.: Design, development and evaluation of novel nanoemulsion formulations for transdermal potential of celecoxib, Acta Pharm. 57 (2007) 315-332.

Ključne riječi: celekoksib, nanoemulzije, mikroemulzije, nanoemulzijksi gel, transdermalna primjena, protuupalno djelovanje

Department of Pharmaceutics, Faculty of Pharmacy, Jamia Hamdard, (Hamdard University), New Delhi-110062, India 